\title{
The PI3K/AKT signaling pathway regulates ABCG2 expression and confers resistance to chemotherapy in human multiple myeloma
}

\author{
LEI WANG, NALIN and YAN LI \\ Department of Hematology, The First Affiliated Hospital of China Medical University, \\ Shenyang, Liaoning 110001, P.R. China
}

Received April 11, 2018; Accepted December 6, 2018

DOI: $10.3892 /$ or.2019.6968

\begin{abstract}
Side population (SP) cells are involved in the development of multidrug resistance (MDR) in human multiple myeloma (MM), due to their cancer stem cell (CSC)-like phenotypes. ATP-binding cassette (ABC) drug transporter proteins have been reported to be closely associated with MDR in leukemia; however, the correlation between ABC proteins and the progression of MM remains unclear. The present study used MM cell lines and clinical samples to determine the role of ABC subfamily $\mathrm{G}$ member 2 (ABCG2) in $\mathrm{MM}$ via flow cytometry, reverse transcription-quantitative polymerase chain reaction and western blotting. SP cells sorted from MM cell lines, including NCI-H929 cells, via fluorescence-activated cell sorting, exhibited CSC-like phenotypes and expressed high levels of ABCG2. Expression of ABCG2 and activation of the phosphatidylinositol 3-kinase (PI3K)/AKT serine/threonine kinase (AKT) signaling pathway was positively associated with the proportion of SP cells in the NCI-H929 cell line. In addition, suppression of the PI3K/AKT pathway using LY294002 or rapamycin counteracted the protective effects of ABCG2 against chemotherapeutic drug treatment. Mechanistically, PI3K/AKT signaling may regulate ABCG2 expression, and ABCG2 may regulate phosphatase and tensin homolog expression via a potential negative feedback loop. Furthermore, SP cell proportion, ABCG 2 expression and PI3K/AKT pathway activation were associated with disease progression in patients with MM. These findings indicated the critical roles of ABCG2 and PI3K/AKT signaling in controlling stemness of MM cells, and suggested a novel strategy for targeting ABCG2 and $\mathrm{PI} 3 \mathrm{~K} / \mathrm{AKT}$ signaling to treat MM with MDR.
\end{abstract}

Correspondence to: Dr Yan Li, Department of Hematology, The First Affiliated Hospital of China Medical University, No. 155 Nanjing North Street, Heping District, Shenyang, Liaoning 110001, P.R. China E-mail: liyan2@medmail.com.cn

Key words: multiple myeloma, cancer stem cells, side population, ABCG2, PI3K/AKT, drug resistance

\section{Introduction}

Multiple myeloma (MM) is a common tumor of the blood, which is characterized by plasma cell colonization and prominent bone marrow damage. The majority of patients with MM eventually exhibit relapse or multidrug resistance (MDR), regardless of chemotherapy, targeted drug therapy or autologous stem cell transplantation. The development of MDR to chemotherapeutic agents remains a major obstacle in the effective treatment of cancer (1). The occurrence and recurrence of MM suggests the presence of cancer stem cells (CSCs), which are responsible for tumor initiation, self-renewal, drug resistance and metastasis (2). CSCs from acute myeloid leukemia, breast cancer, glioma and numerous other types of cancer have been successfully isolated using cancer-type specific surface markers (3-5). However, CSCs have not been isolated from MM, due to the lack of specific surface markers.

Despite the distinct surface markers of MM, CSCs have not been definitively identified. The concept of side population (SP) cells has been widely used as a unique source for studying CSCs when specific markers are not available (6-12). First described by Goodell et al (13), SP cells are a subset of enriched progenitor cells that exhibit CSC-like phenotypes with distinct low staining of Hoechst 33342 in several malignant tumors. Accumulating evidence has indicated that CSCs are highly resistant to conventional cancer therapies and contribute to MDR (14-18). For example, SP cells sorted from glioma and primary esophageal carcinoma have a lower sensitivity to chemotherapy drugs in vitro $(18,19)$. Although a few studies have characterized SP cells compared with main population (MP) cells, the stem-like properties and tumorigenicity of SP cells in MM remains largely unknown.

Although MDR is a multifactorial phenomenon, overexpression of ATP-binding cassette (ABC) drug transporter proteins remains one of the most common mechanisms underlying MDR. It is well known that CSCs often exhibit high $\mathrm{ABC}$ transporter activity, particularly ABC subfamily $\mathrm{G}$ member 2 (ABCG2) activity. ABCG2 is a surface molecule that contributes to drug resistance via the efflux of intracellular drugs $(20,21)$. Phosphatidylinositol 3-kinases (PI3Ks) are a family of lipid kinases that serve critical roles in regulating various cellular processes. With subsequent activation of 
AKT serine-threonine kinase (AKT) and other downstream effectors, such as mammalian target of rapamycin (mTOR), the PI3K pathway is crucial in cancer proliferation and also contributes to MDR in certain types of cancer (22). However, the roles of PI3K/AKT/mTOR signaling in maintaining MM stem cell properties have not been extensively studied $(23,24)$. Therefore, the present study aimed to investigate whether ABCG2 may be used as a surface marker for MM CSCs, and if a correlation exists between ABCG2 expression and $\mathrm{PI} 3 \mathrm{~K} / \mathrm{AKT}$ signaling in SP cells in MM.

\section{Materials and methods}

MM cell lines and primary MM cells. The U266 and NCI-H929 human MM cell lines were originally obtained from American Type Culture Collection (Manassas, VA, USA), and were further cultivated in our laboratory. Cell lines were authenticated using a short-tandem repeat method and were confirmed as mycoplasma contamination-free. Cells were cultured in RPMI-1640 medium (Gibco; Thermo Fisher Scientific, Inc., Waltham, MA, USA) supplemented with $10 \%$ fetal bovine serum (TransGen Biotech Co., Ltd., Beijing, China) and 1\% penicillin/streptomycin (TransGen Biotech Co., Ltd.) at $37^{\circ} \mathrm{C}$ in a humidified incubator containing $5 \% \mathrm{CO}_{2}$.

A total of 30 patients diagnosed with MM, according to the Updated Diagnostic Criteria and Staging System for MM (25), were selected for the present study. A total of 16 patients were men and 14 were women (age, 22-82 years). With regards to the Durie-Salmon (DS) criteria, two samples were DS stage I, five were DS stage II and 23 were DS stage III; in addition, with regards to the International Staging System (ISS) criteria, three samples were ISS stage I, 11 were ISS stage II and 16 were ISS stage III. The control group consisted of 10 samples (three male patients and seven female patients; age, 31-52 years) from healthy individuals without hematological diseases. Patients with MM and control individuals were recruited from the Department of Hematology, China Medical University (Shenyang, China) between January 1, 2015 and December 30, 2015. Bone marrow mononuclear cells were obtained from total bone marrow by density gradient centrifugation; briefly, lymphocyte separation solution (GE Healthcare, Chicago, IL, USA) and bone marrow was added to $15 \mathrm{ml}$ centrifuge tubes and were centrifuged at $400 \mathrm{x} \mathrm{g}$ for $30 \mathrm{~min}$ at room temperature. The present study (AF-SOP-07-1.0-01) was approved by the institutional review board of the First Affiliated Hospital of China Medical University (Shenyang, China), and written informed consent was obtained from all patients prior to their participation, in accordance with the Declaration of Helsinki.

Reagents and antibodies. Hoechst 33342 and Verapamil were obtained from Sigma-Aldrich; Merck KGaA (Darmstadt, Germany). Rabbit polyclonal antibodies against phosphatase and tensin homolog (PTEN; cat. no. 9559), phosphorylated (p)-PI3K (cat. no. 4228), PI3K (cat. no. 4257), p-AKT (cat. no. 4060), AKT (cat. no. 9272), ABCG2 (cat. no. 42078) and $\beta$-actin (cat. no. 4970) were obtained from Cell Signaling Technology, Inc. (Danvers, MA, USA). Arsenic trioxide $\left(\mathrm{As}_{2} \mathrm{O}_{3}\right)$, bortezomib (Bort), LY294002 and rapamypin were purchased from Selleck Chemicals (Houston TX, USA).
Lentiviral infection of ABCG2 in NCI-H929 cells. Lentiviral particles were produced in 293T cells (Shanghai GeneChem Co., Ltd., Shanghai, China) $\left[5 \times 10^{6}\right.$ cells $/ \mathrm{ml}$, cultured in Dulbecco's modified Eagle's medium (DMEM; HyClone; GE Healthcare Life Sciences, Logan, UT, USA) containing $10 \%$ fetal bovine serum (HyClone; GE Healthcare Life Sciences] by transiently co-transfecting control vector pGV358 (DMEM, $37^{\circ} \mathrm{C}, 24 \mathrm{~h}$ ) (obtained from Dr Van Duyne, University of Pennsylvania, Philadelphia, PA, USA) or pGV358-ABCG2 (ABCG2 cDNA was ontained from Shanghai GeneChem Co., Ltd.; GenBank accession no.: NM-004827, https://www. ncbi.nlm.nih.gov/genbank/) with helper plasmids pMD2.G (Plasmid \#12259; Addgene, Inc., Cambridge, MA, USA) and psPAX2 (Plasmid \#12260; Addgene, Inc.) using FuGENE ${ }^{\circledR} \mathrm{HD}$ Transfection Reagent (Promega Corporation, Madison, WI, USA). A total of $24 \mathrm{~h}$ post-infection of NCI-H929 cells $\left(5 \times 10^{5}\right.$ cells $\left./ \mathrm{ml}\right)$ with $\mathrm{ABCG} 2$ or non-specific control (NC) lentiviruses. The lentiviral supernatants were harvested post-transfection and were filtered $(0.45 \mathrm{mM}$ filter) prior to infection of the cell lines at $37^{\circ} \mathrm{C}$ for $24 \mathrm{~h}$ at a multiplicity of infection of 80, the cells were harvested and resuspended in fresh medium. These cells were referred to as NCI-H929/ABCG2 ${ }^{+}$ or NCI-H929/NC cells.

Flow cytometry. NCI-H929, U266 and primary MM cells were suspended at a concentration of $1 \times 10^{6}$ cells $/ \mathrm{ml}$ and were stained with Hoechst 33342 dye $(5 \mu \mathrm{g} / \mathrm{ml})$ in culture medium at $37^{\circ} \mathrm{C}$ for $90 \mathrm{~min}$. Samples were also treated with $50 \mu \mathrm{M}$ Verapamil for $90 \mathrm{~min}$ at $37^{\circ} \mathrm{C}$ as a negative control, which can inhibit the efflux of Hoechst 33342. Propidium iodide (PI; $1 \mu \mathrm{g} / \mathrm{ml}$ ) was added to the cells at $4^{\circ} \mathrm{C}$ for $15 \mathrm{~min}$ prior to flow cytometric analysis. PI-negative (live) cells were initially gated, and the SP-gated cells were defined as the diminished area on the dot plot (Fig. 1A) (26). SP and MP cells were sorted for further experiments using fluorescence-activated cell sorting (FACS) (FACSAria II, BD). NCI-H929 and NCI-H929/ABCG2 ${ }^{+}$cells treated with LY294002 $(20 \mu \mathrm{M})$ or rapamycin $(100 \mathrm{nM})$ at $37^{\circ} \mathrm{C}$ for $72 \mathrm{~h}$ were subjected to the same procedures for SP and MP cell sorting. Cell cycle analysis was performed by fixing cells in $75 \%$ ethanol and staining them with PI, according to the protocol of the cell cycle analysis kit (TransGen Biotech Co., Ltd.).

Determining drug sensitivity using a cell proliferation assay. Drug sensitivity of sorted SP and MP cells was determined using the Cell Counting Kit-8 (CCK-8; Dojindo Molecular Technologies, Inc., Kumamato, Japan), according to the manufacturer's protocol. Briefly, cells were suspended at $1 \times 10^{5}$ cells $/ \mathrm{ml}$ and seeded in a 96-well plate. SP and MP cells were treated with various doses of Bort $(10,25$ and $50 \mathrm{nM})$ or $\mathrm{As}_{2} \mathrm{O}_{3}(1.25,2.5$ and $5 \mu \mathrm{M})$ for $24 \mathrm{~h}$ at $37^{\circ} \mathrm{C}$. Subsequently, CCK-8 reagent $(10 \mu \mathrm{l})$ was added to each well and absorbance was measured at $450 \mathrm{~nm}$ after $1 \mathrm{~h}$. For NCI-H929 and NCI-H929/ABCG2 ${ }^{+}$cells, LY294002 $(20 \mu \mathrm{M})$ or rapamycin $(100 \mathrm{nM})$ was added to the culture medium for $72 \mathrm{~h}$ prior to the addition of $\mathrm{As}_{2} \mathrm{O}_{3}$ or Bort. The ratio of dead cells was calculated using the following equation: Ratio $=[1-(\mathrm{OD}$ value of treatment - OD value of background)/(OD value of control - OD value of background)] x $100 \%$. OD refers to optical density. 
A
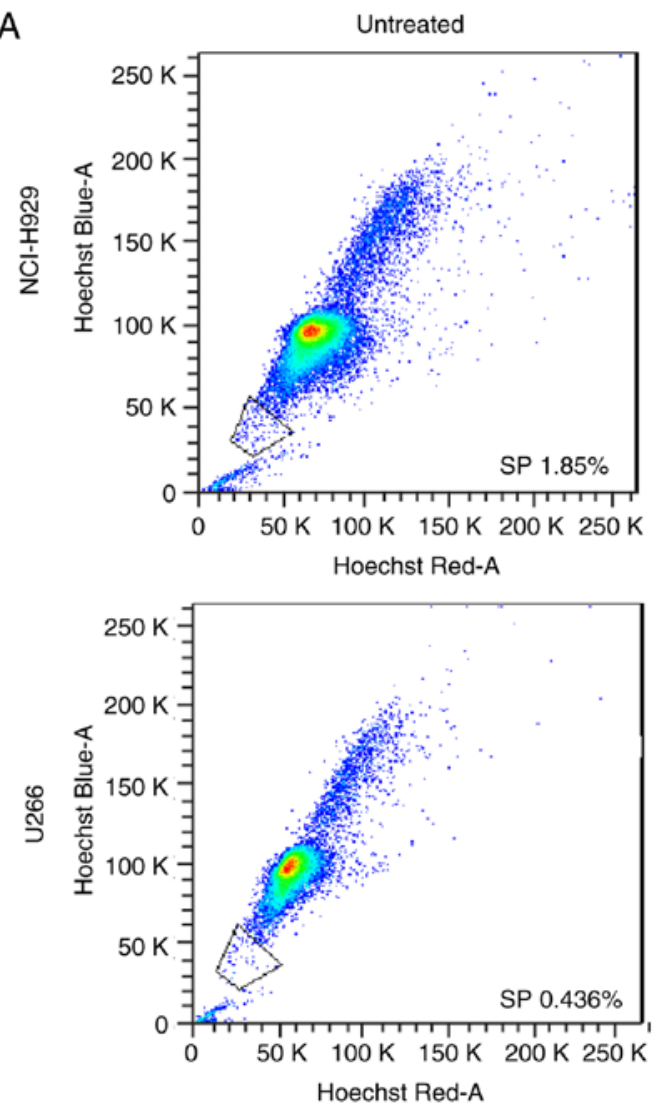

B

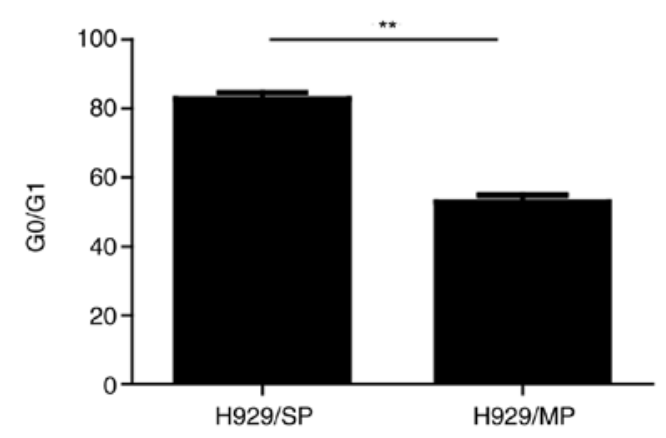

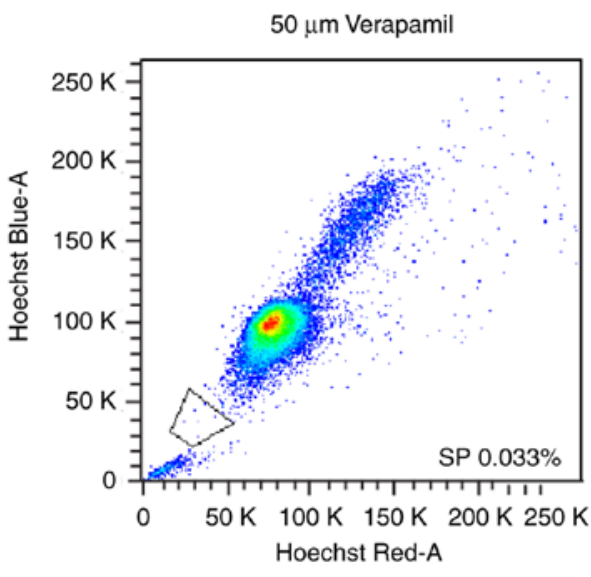

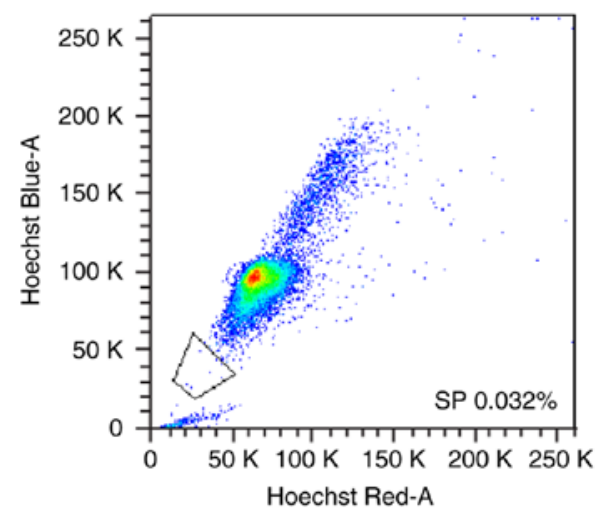

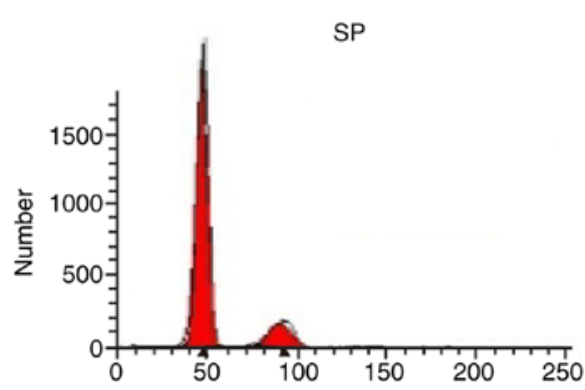

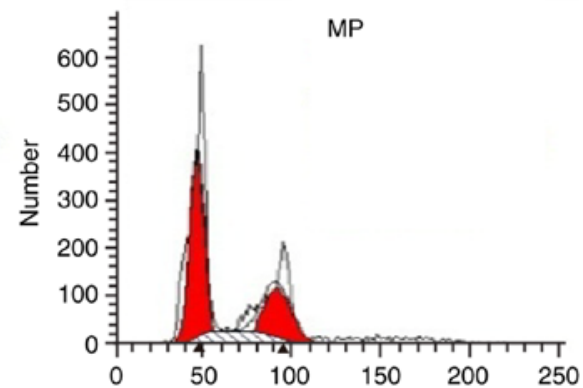

Figure 1. SP cells sorted from MM cell lines share similar biological characteristics with cancer stem cells. (A) Representative flow cytometry profile of SP cells in human MM cell lines, NCI-H929 and U266, with or without Verapamil treatment (50 $\mu \mathrm{M})$. (B) Cell cycle analysis of SP and MP cells isolated from NCI-H929 cells after propidium iodide staining.

Soft agar colony formation assay. The soft agar colony formation assay was performed as previously described (27). Briefly, the soft agar used consisted of an upper layer ( $0.35 \%$ agarose) and a lower layer ( $0.7 \%$ agarose). FACS-sorted SP or MP cells $\left(5 \times 10^{3} /\right.$ test $)$ were inoculated and grown for 14 days in the soft agar. Fresh medium was added to the cells every 3 days, and the number of colonies was counted (colonies contained $>50$ cells) at day 14 under a BX51 microscope (Olympus Corporation, Tokyo, Japan).
Reverse transcription quantitative polymerase chain reaction (RT-qPCR). Bone marrow mononuclear cells were obtained from total bone marrow by density gradient centrifugation. Total RNA was extracted from cells using TRIzol ${ }^{\circledR}$ reagent (Invitrogen; Thermo Fisher Scientific, Inc.), according to the manufacturer's protocol. RNA samples (500 ng each) were reverse transcribed into cDNA using an M-MLV first strand cDNA synthesis kit (Invitrogen; Thermo Fisher Scientific, 
C
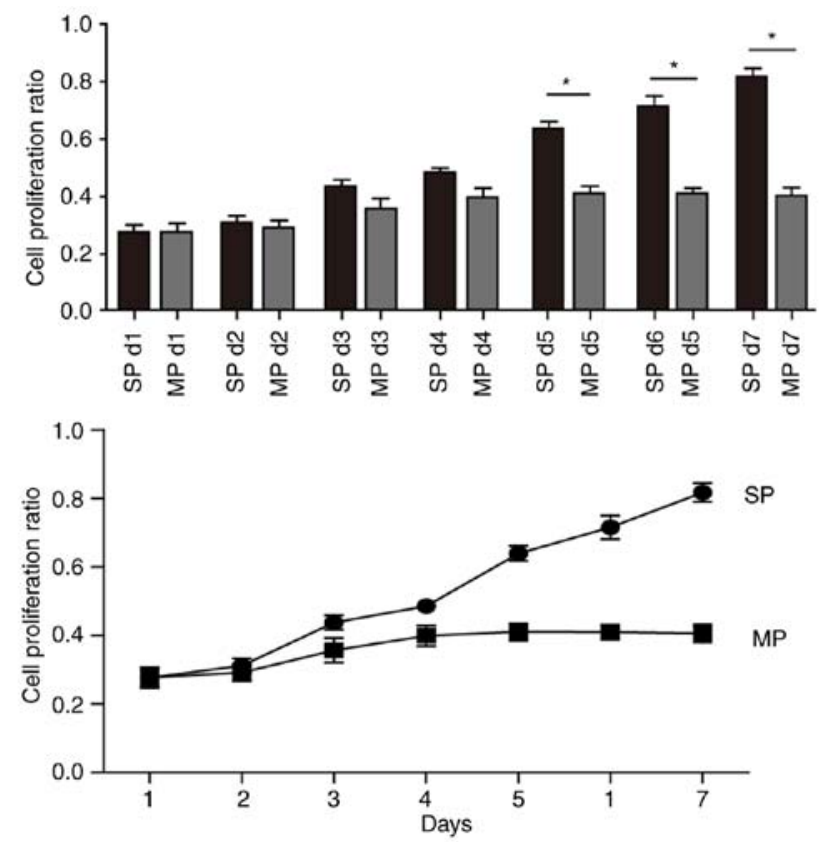

D
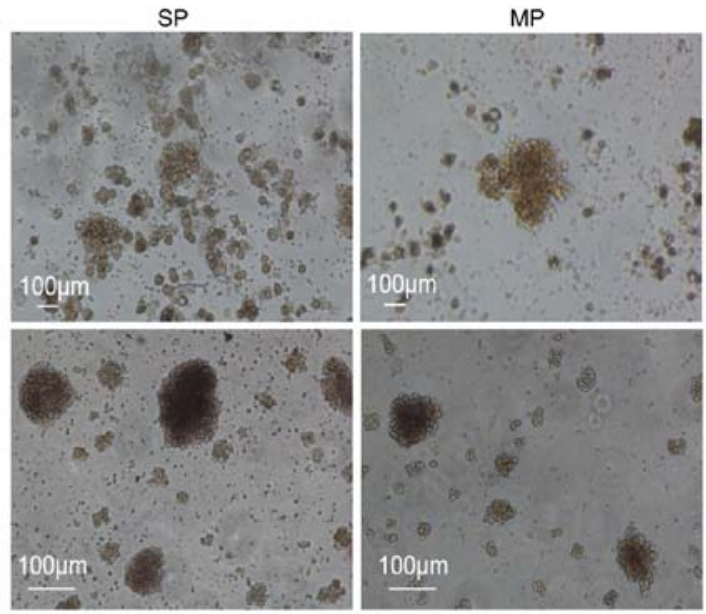

$\mathrm{E}$

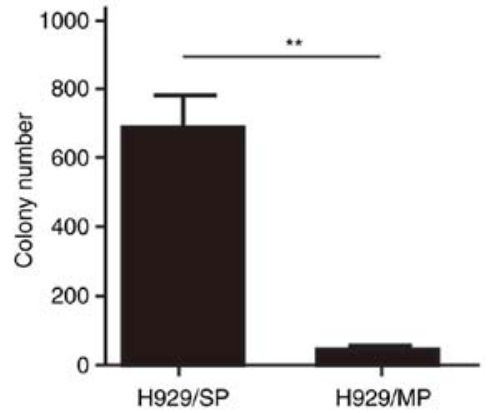

Figure 1. Continued. (C) Cell proliferation curves of SP and MP cells isolated from the NCI-H929 cell line. (D) Representative images of the colony forming ability of SP and MP cells isolated from the NCI-H929 cell line. (E) Summary of colony numbers generated by SP and MP cells isolated from NCI-H929 cells. $n=3$ tests/group. Representative data of three experiments with similar results are presented. ${ }^{*} \mathrm{P}<0.05,{ }^{* *} \mathrm{P}<0.01$. MP, main population; SP, side population.

Inc.), according to the manufacturer's protocol. qPCR was performed using the 7500 real-time PCR system and Power SYBR Green Master Mixture (both Applied Biosystems; Thermo Fisher Scientific, Inc.). The thermocycling conditions ewre as follows: $95^{\circ} \mathrm{C}$ for $5 \mathrm{~min}$ followed by 40 cycles at $95^{\circ} \mathrm{C}$ for $30 \mathrm{sec}, 52^{\circ} \mathrm{C}$ for $30 \mathrm{sec}, 72^{\circ} \mathrm{C}$ for $45 \mathrm{sec}$, and a final step at $62^{\circ} \mathrm{C}$ for $10 \mathrm{~min}$. GAPDH was used as the internal control gene. Fold changes in relative gene expression were calculated according to the $\Delta \Delta \mathrm{Cq}$ method (28). In addition, the amplified products were analyzed by DNA electrophoresis on a $2 \%$ agarose gel and the gels were stained wih ethidium bromide (Beyotime Institute of Biotechnology, Shanghai, China). Primer sequences for specific gene amplification are listed in Table I.

Western blotting. Cells were lysed with Lysis Buffer (Beijing Solarbio Science \& Tecnology Co., Ltd., Beijing, China) and total protein concentration was measured using the Pierce Bicinchoninic Acid Protein Assay kit (Thermo
Fisher Scientific, Inc.). Equal amounts of protein $(50 \mu \mathrm{g})$ were separated by $8 \%$ SDS-PAGE and transferred to polyvinylidene fluoride membranes, which were blocked with ice-cold transfer film buffer $(0.29 \%$ Tris-base, $0.58 \%$ glycine, $0.037 \%$ SDS and $\mathrm{ddH}_{2} \mathrm{O}$ ) for 60-90 min. Primary antibodies against PTEN $(1: 1,000)$, p-PI3K $(1: 1,000)$, PI3K $(1: 1,000)$, p-AKT $(1: 1,000)$, AKT $(1: 1,000), \operatorname{ABCG} 2(1: 1,000)$ and $\beta$-actin $(1: 1,000)$ were applied overnight at $4^{\circ} \mathrm{C}$ at a dilution of 1:1,000.Proteinsweredetected byenhancedchemiluminescence (EMD Millipore, Billerica, MA, USA), following incubation with horseradish peroxidase-conjugated secondary antibodies (1:10,000 dilution; cat. no. HAF008; R\&D Systems China Co., Ltd., Shanghai, China) at room temperature for $1 \mathrm{~h}$. Blots were semi-quantified using ImageJ (V1.8.0; National Institutes of Health, Bethesda, MD, USA).

Statistical analysis. SPSS software 13.0 (SPSS, Inc., Chicago, IL, USA) and GraphPad Prism 5 (GraphPad Software, Inc., La Jolla, CA, ISA) were used for statistical analysis. Data 
Table I. List of primer sequences.

\begin{tabular}{ll}
\hline Gene name & \multicolumn{1}{c}{ Sequence (5' to 3') $^{\prime}$} \\
\hline ABCG2 & F: ATTGAAGCCAAAGGCAGATG \\
& R: TGAGTCCTGGGCAGAAGTTT \\
ABCA3 & F: AGAAATACGGTGCCGGCTATCACA \\
& R: CAATGCCCAGCTCTTTCTGCTTCT \\
ABCB1 & F: GCTCCTGACTATGCCAAAGC \\
& R: TCTTCACCTCCAGGCTCAGT \\
ABCC1 & F: CTGGGCTTATTTCGGATCAA \\
& R: TGAATGGGTCCAGGTCATT \\
PTEN & F: ATACCAGGACCAGAGGAAACC \\
& R: TTGTCATTATCCGCACGCT \\
GAPDH & F: TCCTGCACCACCAACTGCTT \\
& R: GAGGGGCCATCCACAGTCTT \\
\hline
\end{tabular}

ABC, ATP binding cassette; ABCA3, ABC subfamily A member 3; $\mathrm{ABCB} 1, \mathrm{ABC}$ subfamily $\mathrm{B}$ member 1 ; ABCC1, ABC subfamily $\mathrm{C}$ member 1; ABCG2, ABC subfamily G member 2; F, forward; PTEN, phosphatase and tensin homolog; R, reverse.

are presented as the means \pm standard deviation. Differences between two groups were analyzed using Student's t-test. Differences among multiple groups were analyzed using one-way analysis of variance and the Student-Newman-Keuls post hoc test. The correlations between PTEN and ABCG2, PTEN expression and SP\%, and ABCG2 expression and SP\% were assessed using Spearman correlation analysis. All experiments were performed in triplicate with consistent results. ${ }^{*} \mathrm{P}<0.05$ was considered to indicate a statistically signifcant difference, ${ }^{* *} \mathrm{P}<0.01$ was considered to indicate a larger statistically significant difference.

\section{Results}

SP cells sorted from MM cell lines exhibit CSC-like phenotypes and express high levels of ABCG2. The present study stained two human MM cell lines (NCI-H929 and U266) with Hoechst 33342 and PI, in order to determine whether SP cells can be identified in a similar manner as in other tumors. Both MM cell lines contained SP cells, which presented as a distinct 'tail' in the flow cytometric analysis. The proportion of SP cells was $1.79 \pm 0.10 \%$ in the NCI-H929 cell line and $0.46 \pm 0.01 \%$ in the U266 cell line. Since NCI-H929 cells seemed to have a higher proportion of SP cells, SP and MP cells isolated from the NCI-H929 cell line were used for subsequent experiments. $\mathrm{SP}$ cells have inherent properties that distinguish them from MP cells. As shown in Fig. 1B, cell cycle analysis indicated that the percentage of cells in $G_{0} / G_{1}$ phase was significantly higher in SP cells compared with in MP cells $(\mathrm{P}<0.01)$. The majority of SP cells existed in an abnormal $\mathrm{G}_{0} / \mathrm{G}_{1}$ phase, which is consistent with the characteristics of CSCs (29). Furthermore, FACS-sorted SP cells exhibited increased proliferation compared with MP cells under the same culture conditions, as demonstrated by CCK- 8 assays (Fig. 1C). The colony forming ability of SP and MP cells was determined using soft agar colony forming assays. Both SP and MP cells generated colonies, whereas the number of colonies generated by SP cells was significantly greater compared with MP cells $(\mathrm{P}<0.01$; Fig. 1D and E); $13.80 \%$ of SP cells formed visible colonies. These findings suggested that SP cells may possess a prominent self-renewal ability, which is a common characteristic of CSCs.

It is well known that CSCs often exhibit high $\mathrm{ABC}$ transporter activity. The $\mathrm{ABC}$ protein family contains ABC subfamily A member 3 (ABCA3), ABC subfamily $B$ member 1 (ABCB1), $\mathrm{ABC}$ subfamily $\mathrm{C}$ member 1 (ABCC1) and $\mathrm{ABCG}$. Therefore, the present study performed qPCR to investigate the expression of these $\mathrm{ABC}$ family members in $\mathrm{SP}$ and MP NCI-H929 cells. As expected, the mRNA expression levels of $\mathrm{ABCA} 3, \mathrm{ABCB} 1, \mathrm{ABCC} 1$ and $\mathrm{ABCG} 2$ were higher in SP cells compared with in MP cells (Fig. 2A). Notably, SP cells had $\sim 10$ times more ABCG2 transcript compared with MP cells (Fig. 2B). Correspondingly, the protein expression levels of ABCG2 were markedly increased in SP cells compared with in MP cells (Fig. 2C). These data indicated that ABCG2 may be a potential primary factor that maintains the stem cell-like characteristics of SP NCI-H929 cells.

The present study determined the sensitivity of SP and MP cells to two common chemotherapy drugs, Bort and $\mathrm{As}_{2} \mathrm{O}_{3}$. Regardless of the concentrations tested, the survival rates were significantly higher in response to treatment with either Bort (Fig. 2D) or $\mathrm{As}_{2} \mathrm{O}_{3}$ (Fig. 2E) in SP cells compared with in MP cells. Taken together, SP cells from the NCI-H929 cell line exhibited higher ABCG2 expression levels and displayed a more potent chemoresistant phenotype compared with MP cells.

Association between ABCG2 expression, SP cells and the PI3K/mTOR pathway in NCI-H929 cells. To further consolidate the role of ABCG2 in maintaining the phenotype of CSCs, NCI-H929 cells were transfected with either ABCG2-lentivirus (NCI-H929/ABCG2 ${ }^{+}$) or control lentivirus (NCI-H929/NC). Cells infected with green fluorescence protein-tagged lentiviruses were sorted (Fig. 3), and the expression levels of ABCG2, at both mRNA (Fig. 4A) and protein (Fig. 4B) levels, were detected. Considering the critical roles of the PI3K/mTOR pathway in regulating MDR, the present study determined the effects of LY294002 (an inhibitor of PI3K signaling) and rapamycin (an inhibitor of mTOR signaling) on the frequency of SP cells in NCI-H929 and NCI-H929/ABCG2 ${ }^{+}$cell lines. As shown in Fig. 4C and D, the NCI-H929/ABCG2 ${ }^{+}$cell line exhibited a higher percentage of SP cells compared with the NCI-H929 cell line (7.0 vs. 1.8\%; P<0.01). In NCI-H929 and NCI-H929/ABCG2 ${ }^{+}$cell lines, pretreatment with LY294002 or rapamycin significantly reduced the abundance of SP cells. Notably, LY294002 and rapamycin decreased the frequency of SP cells from 7.0 to $\sim 1.5 \%$ in the NCI-H929/ABCG2+ cell line. These data indicated that overexpression of $\mathrm{ABCG} 2$ and activation of the $\mathrm{PI} 3 \mathrm{~K} / \mathrm{mTOR}$ pathway may contribute to SP cell maintenance in the NCI-H929 cell line.

Protective effects of ABCG2 against chemotherapeutic drugs is reversed by PI3K/mTOR pathway inhibition in NCI-H929 


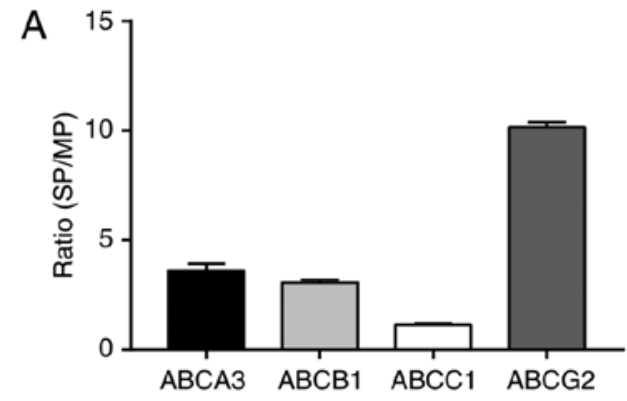

D

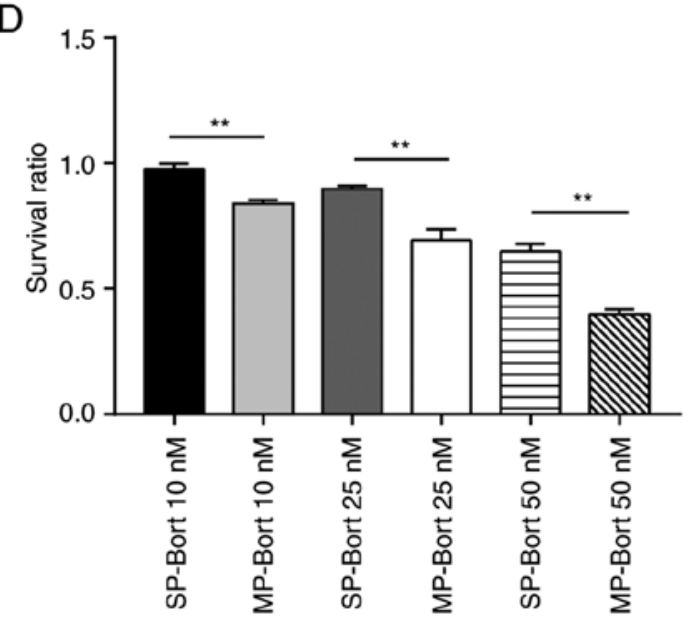

B

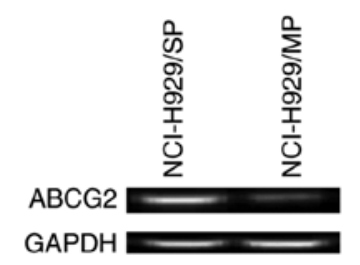

C

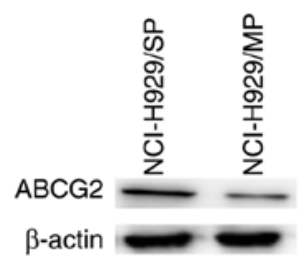

E

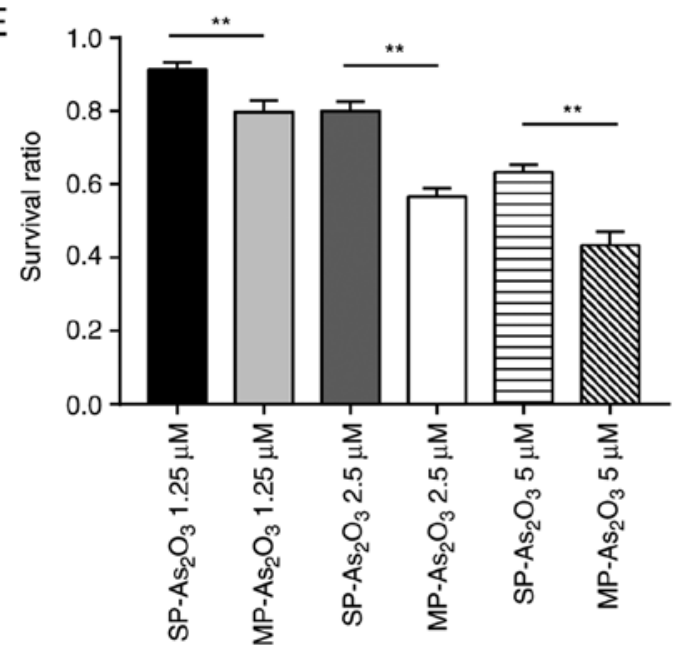

Figure 2. SP cells express high levels of ABCG2 and display more potent chemoresistance than MP cells. (A) Ratios of ABCA3, ABCB1, ABCC1 and ABCG2 transcripts in SP NCI-H929 cells relative to MP NCI-H929 cells. (B) mRNA expression levels of ABCG2, as determined using DNA agarose gel electrophoresis. (C) ABCG2 protein expression levels were increased in SP cells compared with in MP cells. (D and E) Survival ratio of SP and MP cells treated with various doses of (D) Bort or (E) $\mathrm{As}_{2} \mathrm{O}_{3} \cdot{ }^{* *} \mathrm{P}<0.01$. ABC, ATP binding cassette; ABCA3, ABC subfamily A member 3; ABCB1, ABC subfamily B member 1; ABCC1, ABC subfamily C member 1; ABCG2, ABC subfamily G member 2; $\mathrm{As}_{2} \mathrm{O}_{3}$, arsenic trioxide; Bort, bortezomib; MP, main population; SP, side population.

cells. ABCG2 expression is associated with the chemoresistance of SP cells in the NCI-H929 cell line. Consistent with this finding, the cell death rate was significantly lower in NCI-H929/ABCG2 ${ }^{+}$cells compared with NCI-H929 cells, in response to various concentrations of $\mathrm{As}_{2} \mathrm{O}_{3}$ (Fig. 5A) or Bort (Fig. 5B). These data suggested that ABCG2 serves an important role in protecting tumor cells. Since ABCG2 expression and activation of the PI3K/mTOR pathway may be correlated with the proportion of SP cells in the NCI-H929 cell line, the present study detected the sensitivity of tumor cells to chemotherapeutic drugs following inhibition of the PI3K/mTOR pathway. Cell death rates were increased in a dose-dependent manner in response to LY294002 or rapamycin following $\mathrm{As}_{2} \mathrm{O}_{3}$ (Fig. 5C) or Bort (Fig. 5D) treatment in NCI-H929 and NCI-H929/ABCG2+ cells. These findings suggested that inhibition of the PI3K/mTOR pathway in MM may enhance the sensitivity of tumor cells to chemotherapeutic drugs, thus suggesting that inhibition of the PI3K/mTOR pathway counteracts the protective effects of ABCG2.

ABCG2 expression is associated with the activation of PI3K/mTOR signaling in NCI-H929 cells. Since inhibition of the $\mathrm{PI} 3 \mathrm{~K} / \mathrm{mTOR}$ signaling pathway attenuated the protective effects of ABCG2 overexpression on NCI-H929/ABCG2 ${ }^{+}$ cells, the present study aimed to determine whether the $\mathrm{PI} 3 \mathrm{~K} / \mathrm{mTOR}$ pathway regulates ABCG2 expression. The results of RT-qPCR demonstrated that PTEN was downregulated in NCI-H929/ABCG2 ${ }^{+}$cells; PTEN is an inhibitor molecule upstream of PI3K/mTOR signaling (Fig. 6A and B). This finding suggested that $\mathrm{ABCG} 2$ overexpression may be associated with activation of PI3K/mTOR signaling. Conversely, inhibition of PI3K/mTOR signaling by LY294002 or rapamycin reduced ABCG2 expression in NCI-H929 and NCI-H929/ABCG2 ${ }^{+}$ cells (Fig. 6C and D). Subsequently, PI3K/mTOR activity was analyzed by measuring p-PI3K and its downstream target p-AKT in NCI-H929 cells treated with LY294002 or rapamycin. As shown in Fig. 6E, the protein expression levels of p-PI3K and p-AKT were higher in NCI-H929/ABCG2 ${ }^{+}$cells compared with in NCI-H929 cells. In addition, PTEN expression was reduced in NCI-H929/ABCG2+ cells. Notably, ABCG2 expression was markedly decreased following LY294002 or rapamycin treatment of NCI-H929 and NCI-H929/ABCG2 $2^{+}$cells. Therefore, it may be hypothesized that the PI3K/AKT signaling pathway regulated $\mathrm{ABCG} 2$ protein expression, and ABCG2 regulated PTEN protein expression via a possible negative feedback loop.

Proportion of SP cells, ABCG2 expression and activation of the PI3K/AKT pathway are associated with disease progression in patients with MM. A total of 30 patients diagnosed with MM were recruited to this study, in order to determine if the in vitro findings in MM cell lines were applicable in clinical samples (Figs. 7-10). Flow cytometric analyses indicated that the frequencies of SP cells in patient bone marrow samples ranged 
A

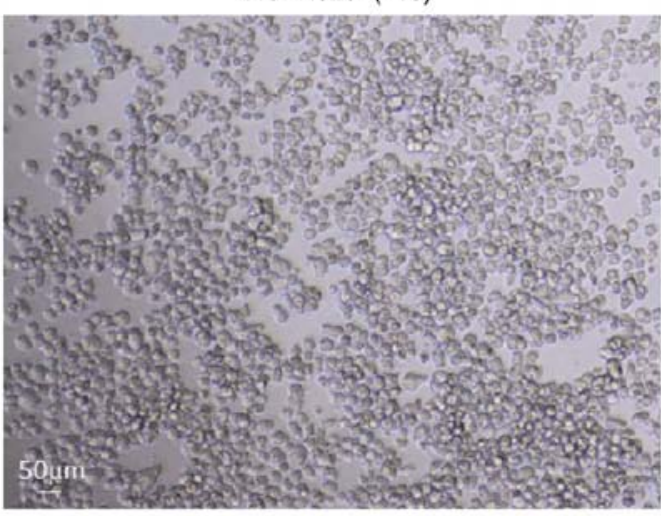

B

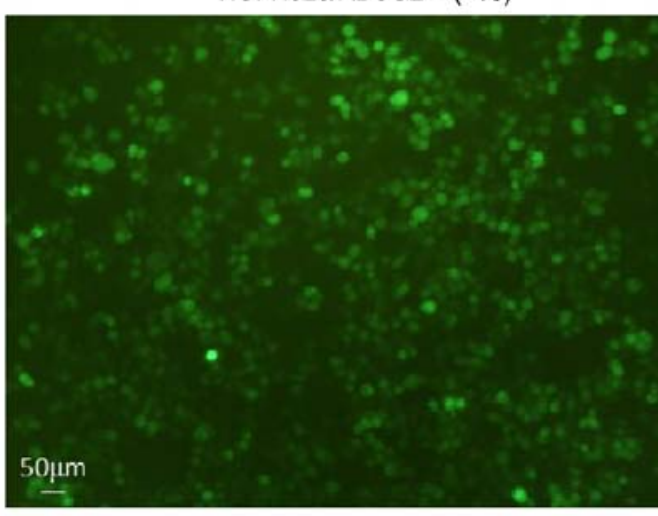

Figure 3. Representative images showing the expression of GFP in lentivirus-infected NCI-H929 cells. (A) Control NCI-H929 cells without infection. (B) NCI-H929 cells infected with lentivirus expressing GFP-tagged ABCG2 protein. Scale bar, $50 \mu \mathrm{m}$. ABC, ATP binding cassette; ABCG2, ABC subfamily G member 2; GFP, green fluorescent protein.

A

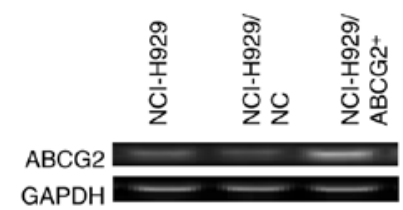

B

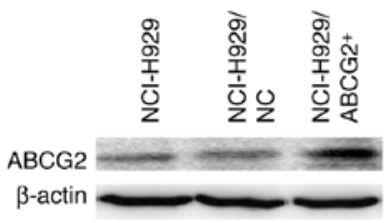

D

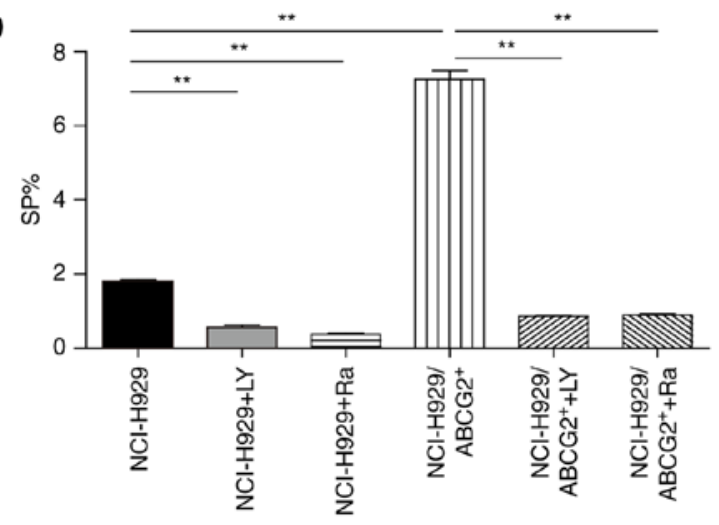

C
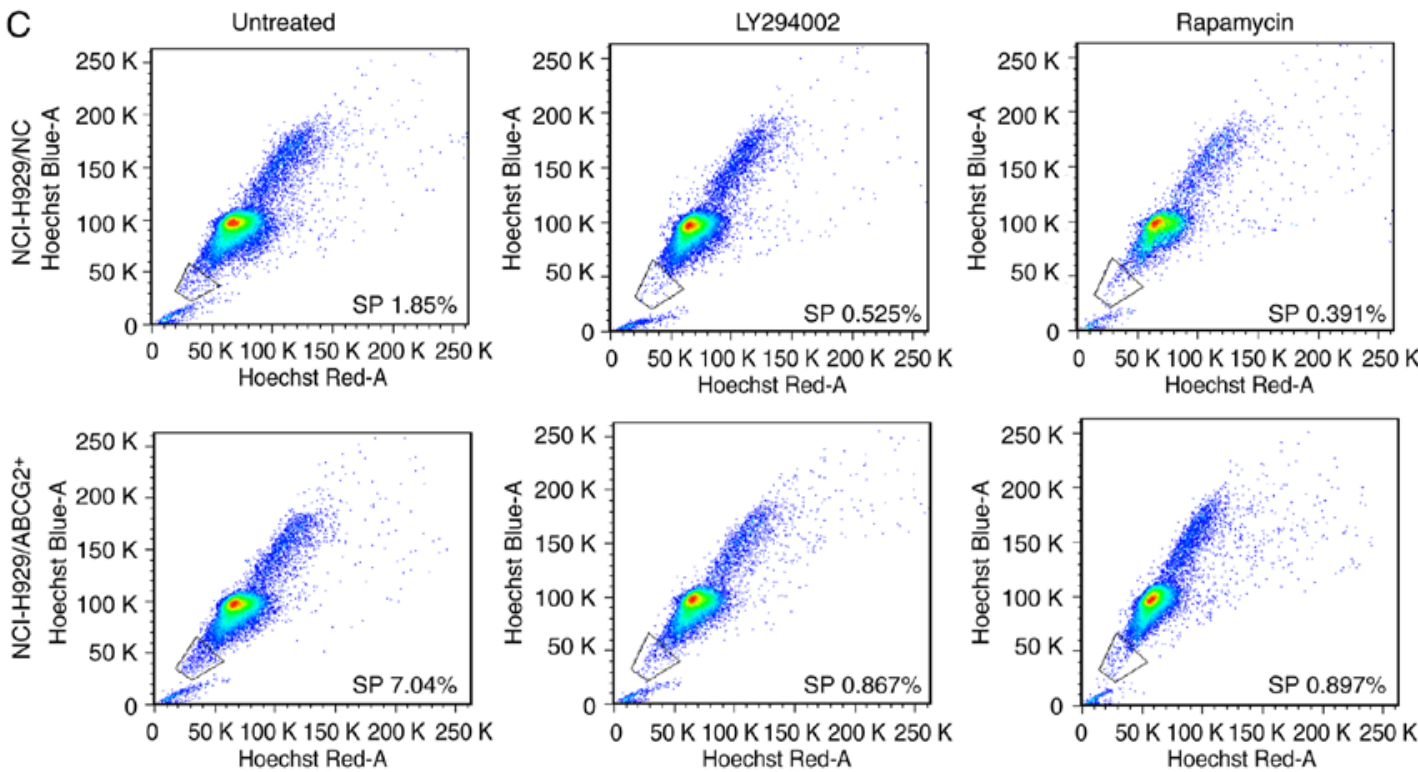

Figure 4. Inhibition of the phosphatidylinositol 3-kinase/AKT serine/threonine kinase pathway reduces the proportion of SP cells in NCI-H929 and NCI-H929/ABCG2 ${ }^{+}$cell lines. ABCG2 (A) mRNA and (B) protein expression levels were markedly higher in NCI-H929/ABCG2 ${ }^{+}$cells compared with control cells (NCI-H929/NC) and uninfected NCI-H929 cells (NCI-H929). (C) Representative flow cytometry plots of SP cells before and after treatment with $20 \mu \mathrm{M} \mathrm{LY} 294002$ or $100 \mathrm{nM}$ rapamycin in NCI-H929 and NCI-H929/ABCG2 ${ }^{+}$cell lines. (D) Proportion of SP cells was significantly higher in the NCI-H929/ABCG2 ${ }^{+}$cell line compared with in the NCI-H929 cell line. $n=3$ tests/group. ${ }^{* *} \mathrm{P}<0.01$. ABC, ATP binding cassette; ABCG2, ABC subfamily G member 2; NC, negative control.

between 0.11 and $3.73 \%$ (Fig. 7A). It was evident that patients with MM had a notably higher proportions of SP cells compared with the control, and the proportions were associated with DS stages, as patients with DS stage III MM had significantly more 
A

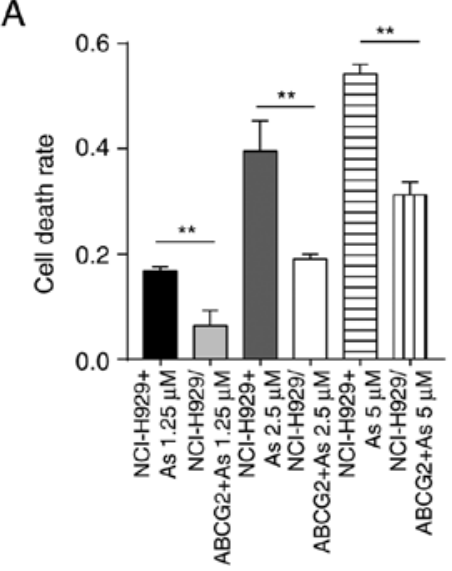

B

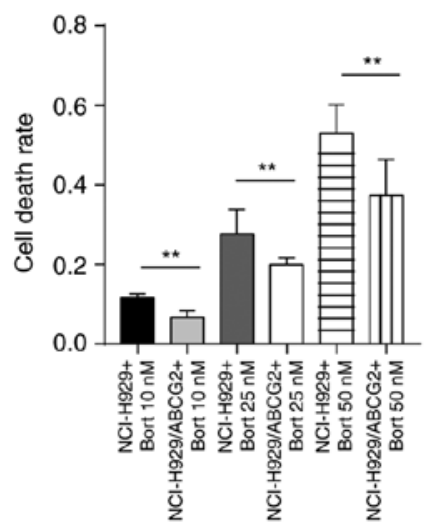

C

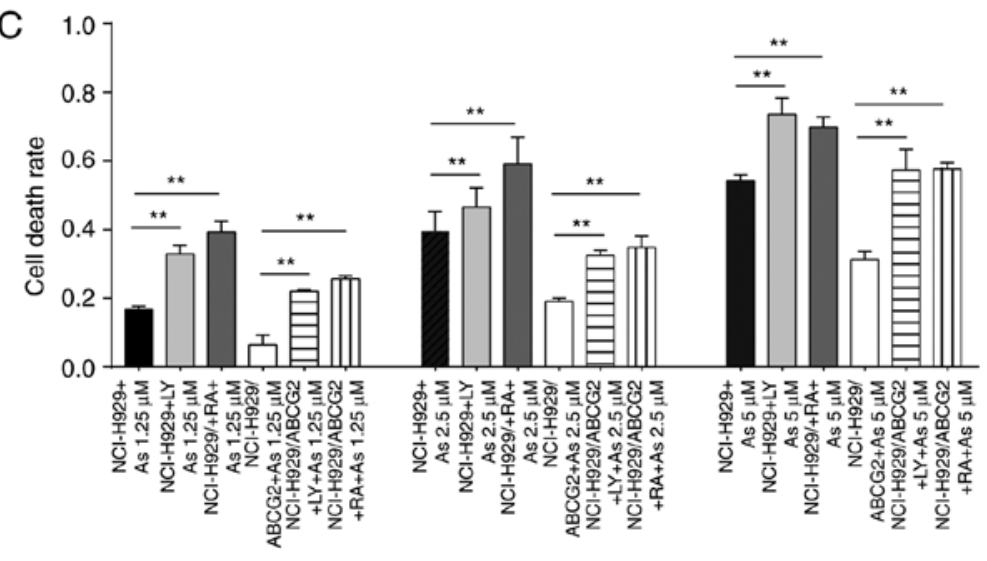

D

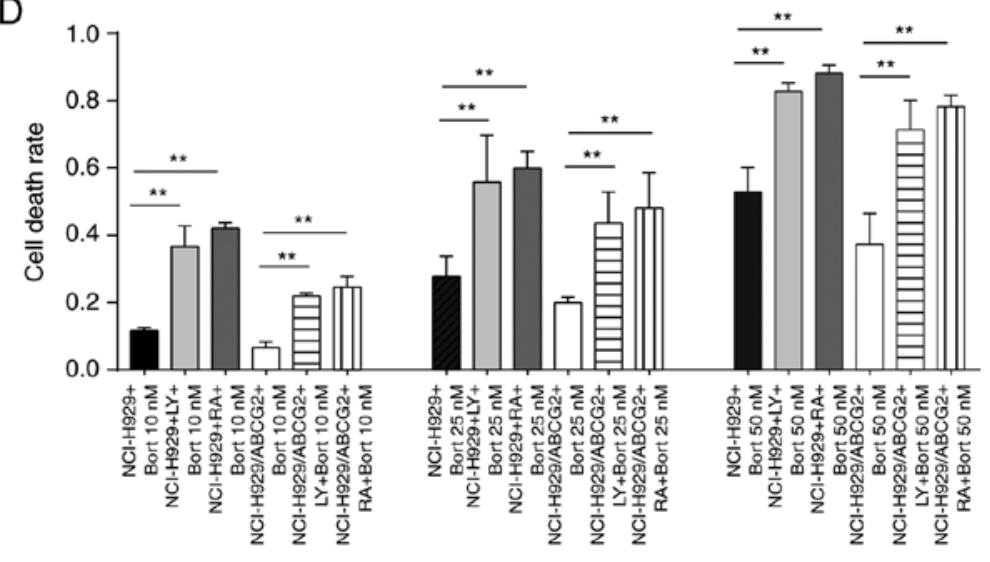

Figure 5. Inhibition of the phosphatidylinositol 3-kinase/mammalian target of rapamycin pathway in NCI-H929 cells enhances their sensitivity to chemotherapeutic drugs. (A and B) Cell death rate was significantly lower in NCI-H929/ABCG2+ cells compared with NCI-H929 cells treated with (A) As $\mathrm{O}_{3}$ or (B) Bort. (C and D) LY or RA treatment significantly increased cell death rate in regular and ABCG2-overexpressing NCI-H929 cells following treatment with various doses of (C) $\mathrm{As}_{2} \mathrm{O}_{3}$ or (D) Bort. ${ }^{* *} \mathrm{P}<0.01$. ABC, ATP binding cassette; ABCG2, ABC subfamily $\mathrm{G}$ member 2; As $\mathrm{O}_{3}$, arsenic trioxide; Bort, bortezomib; LY, LY294002; RA, rapamycin.

A

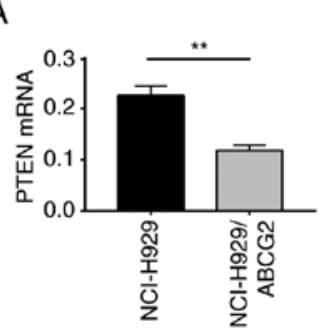

B

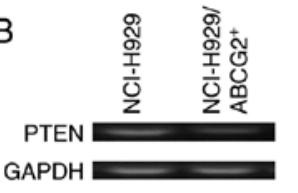

C
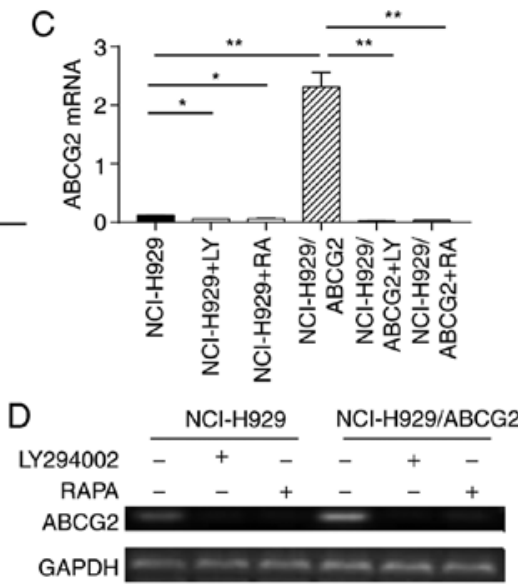

E

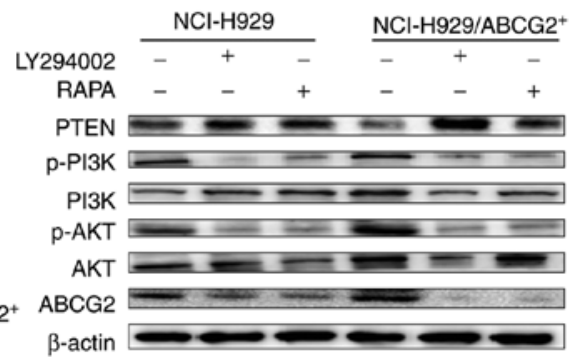

$\beta$-actin

Figure 6. The PI3K/AKT signaling pathway regulates ABCG2 protein expression in NCI-H929 cells. (A and B) PTEN mRNA expression was decreased in NCI-H929/ABCG2 $2^{+}$cells compared with in control NCI-H929 cells. (A) Summary data and (B) representative images of DNA agarose gel electrophoresis are shown. (C and D) ABCG2 mRNA expression was increased in NCI-H929/ABCG2 ${ }^{+}$cells compared with in control NCI-H929 cells, whereas LY294002 or RAPA downregulated ABCG2 expression in both cell types. (C) Summary data and (D) representative images of DNA agarose gel electrophoresis are shown. $\mathrm{n}=3$ tests/group. (E) Association between PI3K/AKT signaling and ABCG2 protein expression in NCI-H929 cells. Whereas PTEN protein levels were decreased, ABCG2, p-PI3K and p-AKT protein levels were increased in NCI-H929/ABCG2 ${ }^{+}$cells compared with in control NCI-H929 cells. LY294002 or RAPA treatment decreased p-PI3K, p-AKT and ABCG2 protein levels in NCI-H929 and NCI-H929/ABCG2 ${ }^{+}$cells. ${ }^{*} \mathrm{P}<0.05,{ }^{* * *} \mathrm{P}<0.01$. ABCG2, ABC subfamily G member 2; AKT, AKT serine/threonine kinase; p, phosphorylated; PI3K, phosphatidylinositol 3-kinase; PTEN, phosphatase and tensin homolog; RAPA, rapamycin.

SP cells compared with patients with DS stage I-II MM (Fig. 8A). However, the proportion of SP cells in patients with MM was not associated with sex (male vs. female, $\mathrm{P}=0.321)$, age ( $<60 \mathrm{vs}$. $>60$ years, $\mathrm{P}=0.309$ ) or ISS stage (I-II vs. III, $\mathrm{P}=0.813$ ) (Fig. 7B). 

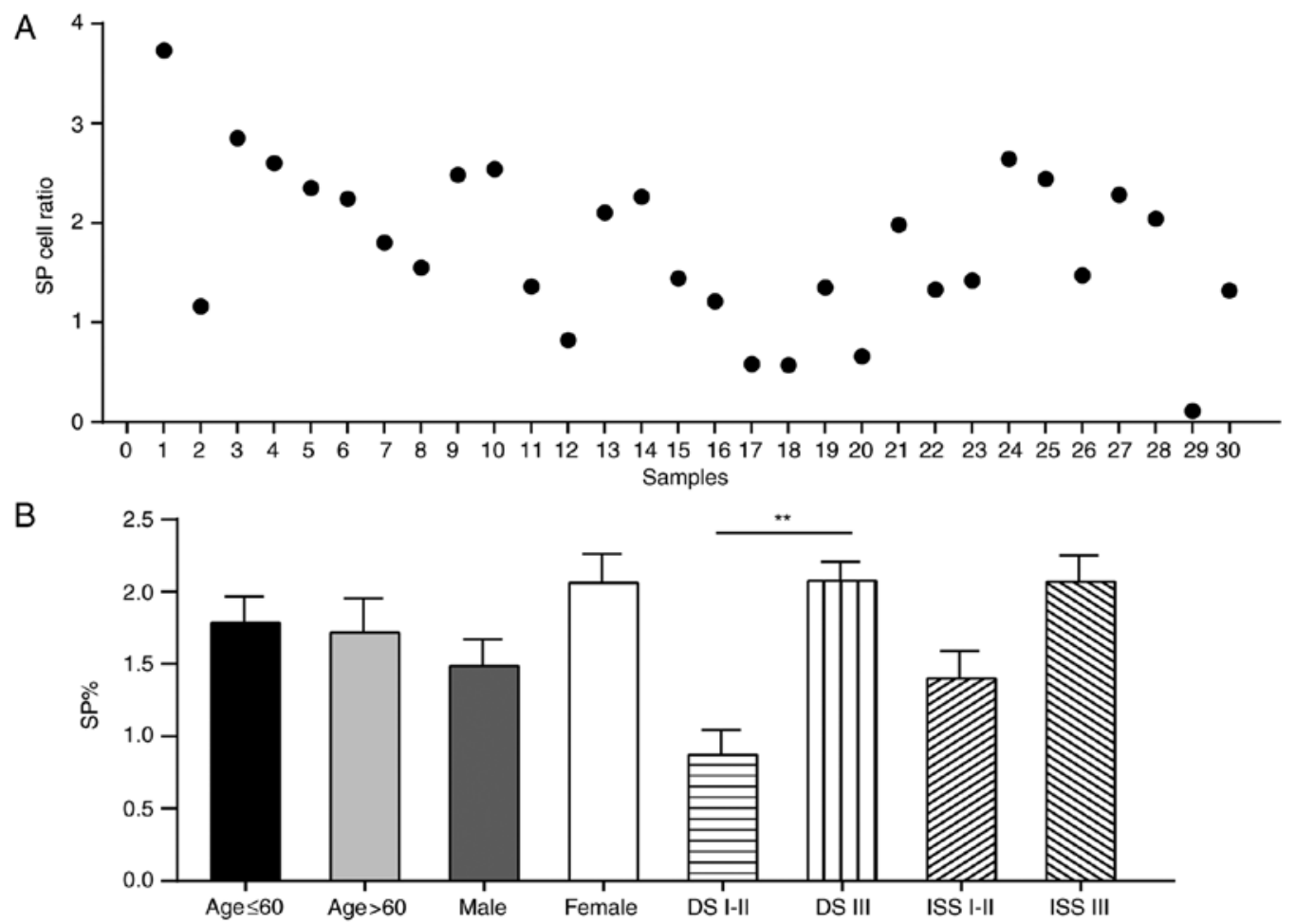

Figure 7. Association between the proportion of SP cells and clinical characteristics of patients with MM. (A) Distribution of SP cells in patients with MM. The proportion of SP cells ranged between 0.11 and $3.73 \%$ in the bone marrow of patients with MM (n=30). (B) Proportion of SP cells in patients with MM was associated with DS stage (I-II vs. III; P=0.047), but not associated with gender (male vs. female; $\mathrm{P}=0.321$ ), age $(<60$ vs. $>60$ years; P=0.309) or ISS stage (I-II vs. III; P=0.813). ${ }^{* *} \mathrm{P}<0.01$. DS, Durie-Salmon; ISS, International Staging System; MM, multiple myeloma; SP, side population.

A

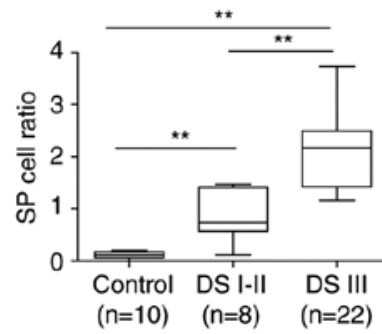

B

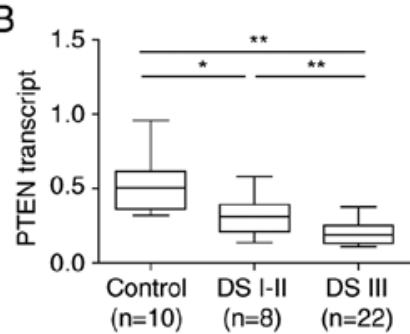

C

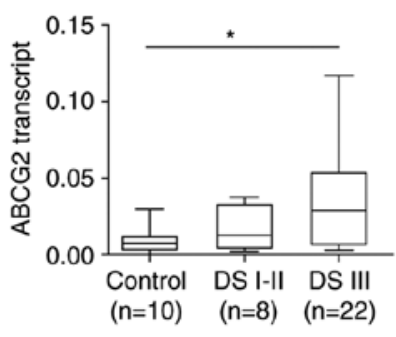

D

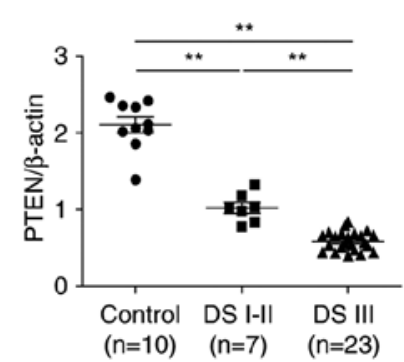

E

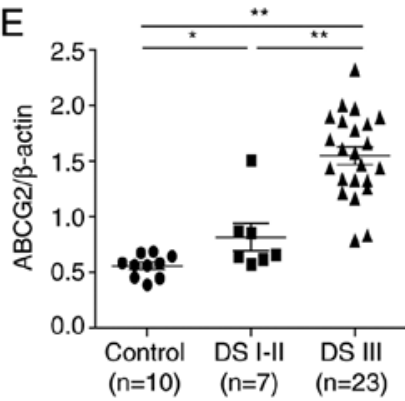

$\mathrm{F}$

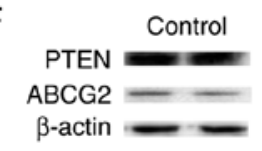

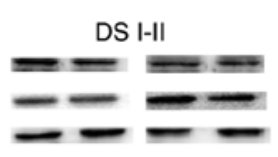

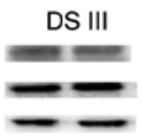

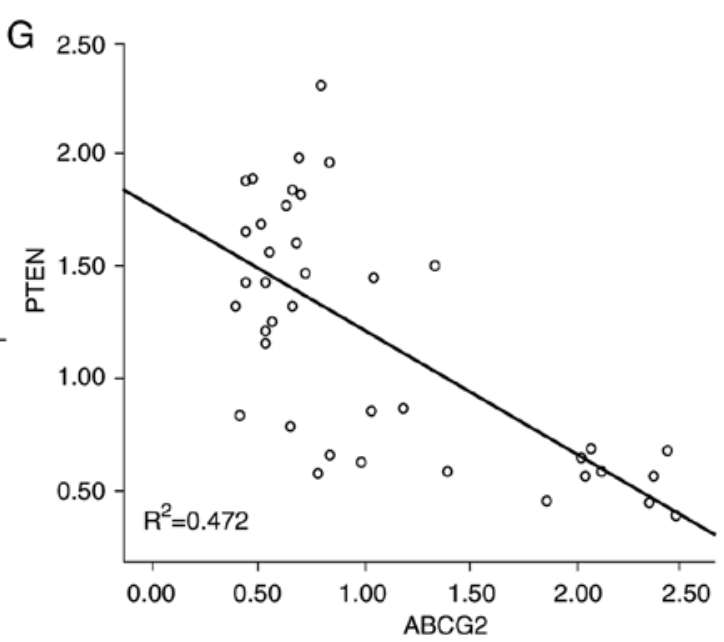

Figure 8. MM disease progression is associated with the proportion of SP cells and ABCG2 expression $\left({ }^{*} \mathrm{P}<0.05,{ }^{* *} \mathrm{P}<0.01\right)$. (A) In patients with MM, the proportion of SP cells in bone marrow increased with disease progression. (B) PTEN mRNA expression significantly decreased with MM disease progression. (C) ABCG2 mRNA expression was significantly increased in patients with DS III MM compared with healthy controls. (D) PTEN protein expression was significantly decreased with MM disease progression. (E) ABCG2 protein expression was significantly increased with MM disease progression. (F) Representative blots for PTEN and ABCG2 in patients with MM and controls. (G) PTEN protein expression was negatively correlated with ABCG2 protein expression in all subjects $\left(\mathrm{P}<0.0001, \mathrm{R}=-0.680, \mathrm{R}^{2}=0.472\right) . \mathrm{n}=10$ healthy controls; $\mathrm{n}=8$ patients with DS I-II MM; $\mathrm{n}=22$ patients with DS III MM. ABCG2, ABC subfamily G member 2; DS, Durie-Salmon; MM, multiple myeloma; PTEN, phosphatase and tensin homolog; SP, side population. 
A

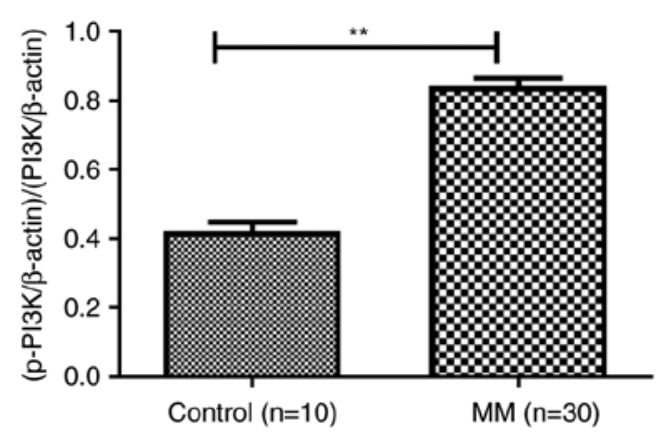

$\mathrm{B}$

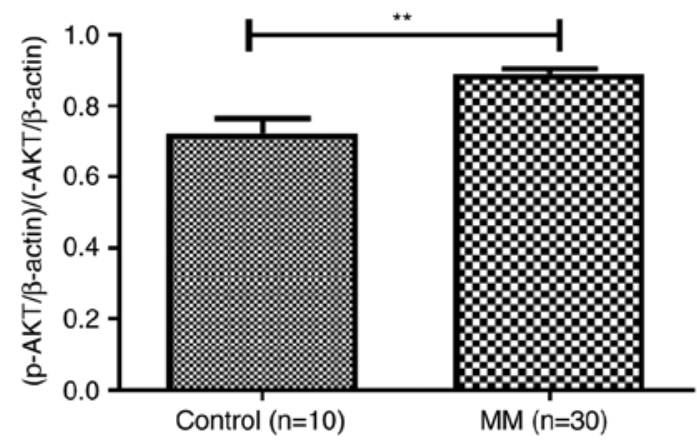

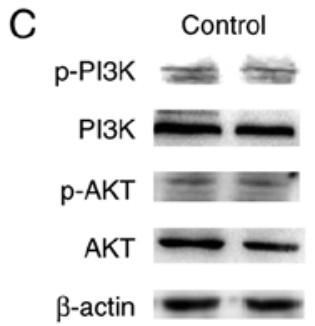

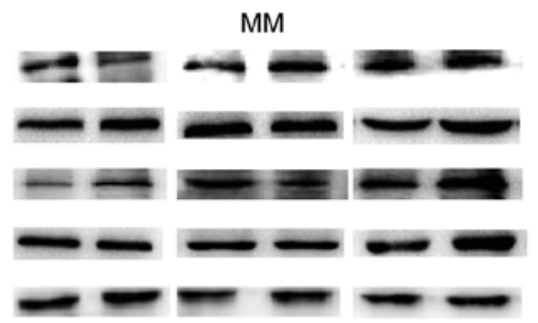

Figure 9. Activation of the PI3K/AKT pathway is enhanced in MM. (A and B) The PI3K/AKT signaling pathway was enhanced in patients with MM compared with in healthy controls, as evidenced by upregulated levels of (A) p-PI3K and (B) p-AKT in the bone marrow of patients with MM $\left(^{* *} \mathrm{P}<0.01\right)$. (C) Representative blots for p-PI3K, PI3K, p-AKT and AKT in patients with MM and controls. $\mathrm{n}=10$ healthy controls; $\mathrm{n}=30$ patients with MM. AKT, AKT serine/threonine kinase; MM, multiple myeloma; p, phosphorylated; PI3K, phosphatidylinositol 3-kinase.
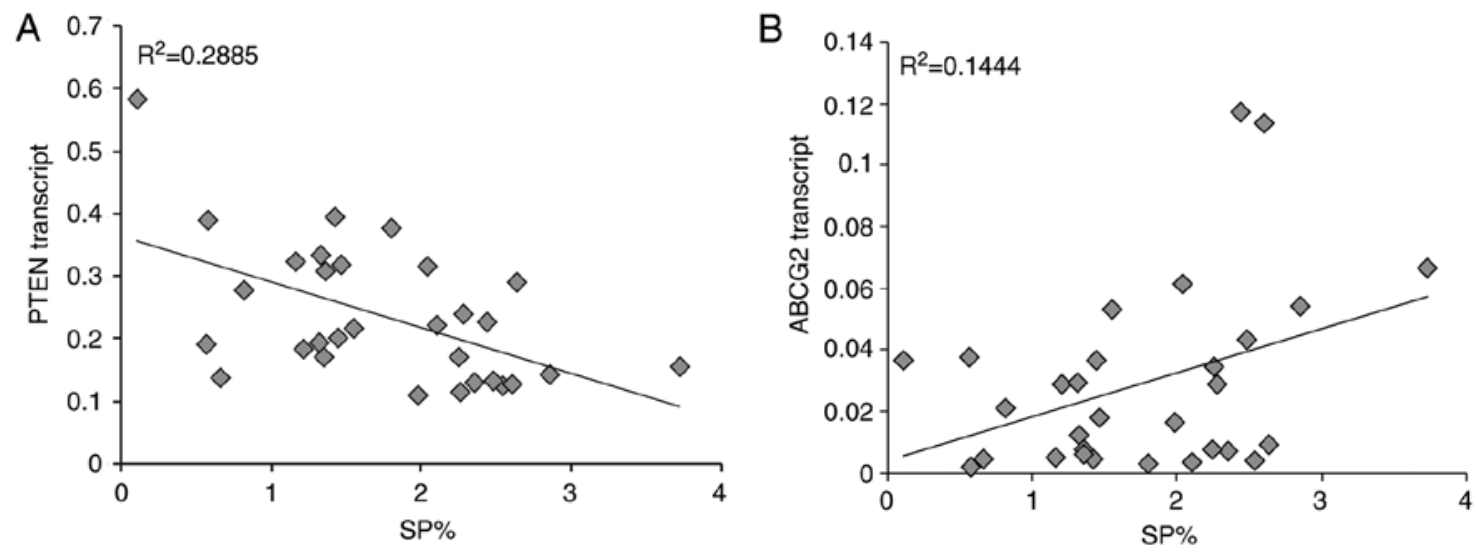

Figure 10. Correlation between the proportion of SP cells and PTEN or ABCG2 expression in patients with MM. (A) There was a significant negative correlation between PTEN transcription and the proportion of SP cells in the bone marrow of patients with $M M\left(R^{2}=0.2885\right)$. (B) There was a significant positive correlation between ABCG2 transcription and the proportion of SP cells in the bone marrow of patients with $M M\left(R^{2}=0.1444\right)$. $n=30$ patients with $M M$. ABCG2, ABC subfamily G member 2; MM, multiple myeloma; PTEN, phosphatase and tensin homolog; SP, side population.

The patient samples were then divided into three groups (Control, patients with DS I-II MM and patients with DS III MM), and the mRNA and protein expression levels of ABCG2 and PTEN were measured. Compared with in the control samples, the mRNA expression levels of PTEN were significantly lower in patients with MM, particularly in DS III patients (Fig. 8B). Conversely, the mRNA expression levels of ABCG2 were significantly higher in patients with DS III MM compared with in the control group. However, there was no significant difference between DS I-II patients and the control group; this may be due to the small sample size (Fig. 8C).

Notably, a significant negative correlation was detected between PTEN mRNA expression and the proportion of SP cells $\left(R^{2}=0.2885\right)$, whereas a significant positive correlation was detected between ABCG2 mRNA expression and the proportion of SP cells $\left(\mathrm{R}^{2}=0.1444\right)$ in patients with MM (Fig. 10). Accordingly, similar protein expression patterns of PTEN and ABCG2 (Fig. 8D-F) were identified among the control group, and DS I-II patient and DS III patient groups. Specifically, PTEN protein levels were negatively correlated with ABCG2 protein levels in all subjects $\left(\mathrm{P}<0.01, \mathrm{R}^{2}=0.472\right.$ (Fig. 8G). In addition, increased levels of p-PI3K (Fig. 9A) and p-AKT (Fig. 9B and C) were detected in patients with MM, thus indicating the importance of the $\mathrm{PI} 3 \mathrm{~K} / \mathrm{AKT}$ signaling pathway in MM pathogenesis.

\section{Discussion}

The global incidence of MM is increasing annually; however, there is currently no optimal treatment for MM. Patients 
receiving chemotherapy endure varying degrees of pain; therefore, it is necessary to develop novel treatments to improve the prognosis of MM. Generally, MM CSCs are associated with chemoresistance, which is the primary cause for clinical failure of the complete elimination of MM cells. In the present study, SP cells were identified and MM CSC-like cells were isolated from MM cell lines and patient samples. The present investigation suggested that ABCG2 may be an indicator of $\mathrm{MM}$ disease progression, and the reciprocal regulation identified between ABCG2 and the PI3K/AKT pathway provided novel approaches to advance MM therapy in the future.

The identification of SP cells from NCI-H929 and U266 MM cell lines is consistent with the literature. Jakubikova et al (30) reported that $0.5-2.5 \%$ of cells in MM cell lines are SP cells. As the present study did not analyze MDR cell lines, the proportion of SP cells was fewer than what has been reported in the literature. In addition to increased cell cycle arrest at $\mathrm{G}_{0} / \mathrm{G}_{1}$ phase and increased self-renewal, the expression levels of $\mathrm{ABCA} 3, \mathrm{ABCB} 1, \mathrm{ABCC} 1$ and $\mathrm{ABCG} 2$ were significantly increased in SP cells compared with in MP cells. Notably, the expression levels of ABCG2 were $\sim 10$ times higher in SP cells compared with in MP cells. These findings suggested that ABCG2 may be one of the most important ABC family members for maintaining the CSC-like biological characteristics of SP cells. This observation is consistent with reports that the ABCG2 transporter is the most specific SP cell marker in solid tumours (31). The survival rate of SP cells was significantly higher than MP cells in response to $\mathrm{As}_{2} \mathrm{O}_{3}$ or Bort. This finding indicated that SP cells may possess lower sensitivity to chemotherapeutic agents compared with MP cells. The present study revealed that SP cells shared similar characteristics with CSCs; however, the surface markers of MM CSCs were not clear (32). It may be hypothesized that targeting SP cells is an effective strategy to eradicate malignant tumors of the blood system, particularly if SP cells can be located and targeted according to the expression pattern of ABCG2.

It has been reported that $\mathrm{ABCG} 2$ exists in both normal and tumor tissues, including in gynecological cancer, prostate cancer, respiratory system tumors, digestive system tumors and blood system tumors (33-35). Since ABCG2 is highly expressed in some CSCs, ABCG2 may be considered a surface marker for CSCs. The present study aimed to explore the biological function of ABCG2 in MM. The results revealed that the death rate of NCI-H929/ABCG2 $2^{+}$cells was significantly lower compared with NCI-H929 cells following treatment with chemotherapeutic drugs. NCI-H929/ABCG2 $2^{+}$cells exhibited low sensitivity to chemotherapeutic agents, indicating that ABCG2 overexpression may have a protective effect on tumor cells. Conversely, the death rate of NCI-H929 and NCI-H929/ABCG2 $2^{+}$cells was increased when the PI3K/AKT pathway was inhibited, thus suggesting that suppressing the PI3K/AKT signaling pathway may counteract the protective effects of ABCG2 overexpression. It is necessary to further study whether the occurrence, development and prognosis of $\mathrm{MM}$ can be altered through regulating the biological behavior of ABCG2.

The PI3K/AKT signaling pathway serves an important role in the occurrence and development of tumors. Activation of the PI3K/AKT pathway has been associated with an increased incidence of leukemia (26); however, the roles of PI3K/AKT signaling in CSCs from MM remain largely unclear. In the present study, NCI-H929/ABCG2 ${ }^{+}$cells exhibited decreased PTEN and increased p-PI3K and p-AKT expression compared with in control NCI-H929 cells; ABCG2 was also negatively correlated with PTEN expression in MM. PTEN deficiencies are closely associated with tumor incidence, including prostate cancer, and significantly higher levels of p-PI3K and p-AKT in leukemia (23). Notably, the present results in NCI-H929 and NCI-H929/ABCG2 ${ }^{+}$cells suggested that the PI3K/AKT signaling pathway may regulate the proportion of SP cells and ABCG2 expression. Therefore, it may be concluded that PTEN regulates $\mathrm{SP}$ cell frequency and $\mathrm{ABCG} 2$ expression via the $\mathrm{PI} 3 \mathrm{~K} / \mathrm{AKT}$ pathway in MM.

SP cells have been detected in numerous solid tumors (36-38) and hematological malignancies $(39,40)$. In an early study on MM, SP cells were detected in 18 out of 21 samples; the inability to detect SP cells in the remaining three samples was likely due to biological polymorphisms (41). In the present study, the proportion of SP cells in patients with MM was significantly higher compared with in the control group. Further analysis indicated that the proportion of SP cells was positively associated with DS stages; patients with DS III MM had higher percentages of SP cells compared with patients with DS I-II MM. Therefore, it may be suggested that the proportion of SP cell was associated with MM disease progression.

Loss of PTEN increases the percentage of SP cells in glioma (18), which is consistent with the present finding that PTEN was significantly reduced in MM. Specifically, PTEN in patients with DS III MM was significantly lower compared with in patients with DS I-II, suggesting that PTEN may be involved in MM pathogenesis and closely associated with disease progression. Furthermore, a negative correlation was identified between the proportion of SP cells and the expression levels of PTEN. ABCG2 protein expression in patients with DS III MM was significantly higher compared with in patients with DS I-II MM, indicating that ABCG2 is an indicator of disease progression and prognosis. Conversely, PTEN protein expression was significantly negatively correlated with ABCG2 protein expression. The PI3K/AKT pathway has been reported to serve an important role in the maintenance of SP cells in primary esophageal carcinoma (19). Consistent with this finding, the present study suggested that PTEN-mediated PI3K/AKT signaling may contribute to the proportion of SP cells in MM, possibly via regulating ABCG2 expression.

In conclusion, SP cells sorted from MM cell lines exhibited high ABCG2 expression and shared similar biological characteristics with CSCs. ABCG2 protected MM cells against the cytotoxicity of chemotherapeutic drugs and was regulated by PTEN-mediated PI3K/AKT signaling in NCI-H929 cells. Inhibition of the PI3K/AKT pathway by LY294002 or rapamycin significantly decreased the proportion of SP cells and enhanced the sensitivity of NCI-H929 cells to chemotherapeutic drugs. The proportion of SP cells, ABCG2 expression and activation of the PI3K/AKT pathway were all positively associated with disease progression in patients with MM. The present study offers insights into regulation of the proportion of SP cells and provides a novel strategy to overcome resistance of MM to existing therapies by targeting the ABCG2 and PI3K/AKT signaling axis. 


\section{Acknowledgements}

The authors would like to thank Dr Pingping Wang, Dr Yazhu Wang and Dr Yue Wang (Department of Hematology, The First Affiliated Hospital of China Medical University) for providing technical assistance.

\section{Funding}

The present study was supported by the National Natural Science Foundation of China (grant no. 81600117).

\section{Availability of data and materials}

All data generated or analyzed during this study are included in this published article.

\section{Authors' contributions}

LW, NL and YL conceived and designed the experiments. LW performed the experiments, analyzed the data and wrote the paper. YL contributed with reagents/materials/analytical tools, critically read the manuscript and provided technical assistance. All authors read and approved the final manuscript.

\section{Ethics approval and consent to participate}

The present study (AF-SOP-07-1.0-01) was approved by the institutional review board of the First Affiliated Hospital of China Medical University, and written informed consent was obtained from all patients prior to their participation, in accordance with the Declaration of Helsinki.

\section{Patient consent for publication}

Patients provided consent for publication.

\section{Competing interests}

The authors declare that they have no competing interests.

\section{References}

1. Nikesitch N, Lee JM, Ling S and Roberts TL: Endoplasmic reticulum stress in the development of multiple myeloma and drug resistance. Clin Transl Immunol 7: e1007, 2018.

2. Issa ME, Cretton S and Cuendet M: Targeting multiple myeloma cancer stem cells with natural products-lessons from other hematological malignancies. Planta Med 83: 752-760, 2017.

3. Bonnet D and Dick JE: Human acute myeloid leukemia is organized as a hierarchy that originates from a primitive hematopoietic cell. Nat Med 3: 730-737, 1997.

4. Al-Hajj M, Wicha MS, Benito-Hernandez A, Morrison SJ and Clarke MF: Prospective identification of tumorigenic breast cancer cells. Proc Natl Acad Sci USA 100: 3983-3988, 2003.

5. Clarke RB, Anderson E, Howell A and Potten CS: Regulation of human breast epithelial stem cells. Cell Prolif 1: 45-58, 2003.

6. Dai Y, Liu S, Zhang WQ, Yang YL, Hang P, Wang H, Cheng L, Hsu PC, Wang YC, Xu Z, et al: YAP1 regulates ABCG2 and cancer cell side population in human lung cancer cells. Oncotarget 8: 4096-4109, 2017.

7. Prasanphanich AF, White DE, Gran MA and Kemp ML: Kinetic modeling of ABCG2 transporter heterogeneity: A quantitative, single-cell analysis of the side population assay. PLoS Comput Biol 12: e1005188, 2016.
8. Wei Z, Liu Y, Wang Y, Zhang Y, Luo Q, Man X, Wei F and Yu X: Downregulation of Foxo3 and TRIM31 by miR-551b in side population promotes cell proliferation, invasion, and drug resistance of ovarian cancer. Med Oncol 33: 126, 2016.

9. Jiang Y, Gao H, Liu M and Mao Q: Sorting and biological characteristics analysis for side population cells in human primary hepatocellular carcinoma. Am J Cancer Res 6: 1890-1905, 2016.

10. Gu H, Wu XY, Fan RT, Wang X, Guo YZ and Wang R: Side population cells from long-term passage non-small cell lung cancer cells display loss of cancer stem cell-like properties and chemoradioresistance. Oncol Lett 12: 2886-2893, 2016.

11. Liu H, Shi B, Yan Y, Niu L, Zhou Y, Cai H and Ge G: CXCR4 promotes growth and sphere formation of hypoxic breast cancer side 7 population cells via activation of c-Jun/ABCG2 pathway. Oncol Res 2016.

12. Wei Z, Lv S, Wang Y, Sun M, Chi G, Guo J, Song P, Fu X, Zhang S and Li Y: Biological characteristics of side population cells in a self-established human ovarian cancer cell line. Oncol Lett 12: 41-48, 2016.

13. Goodell MA, Brose K, Paradis G, Conner AS and Mulligan RC: Isolation and functional properties of murine hematopoietic stem cells that are replicating in vivo. J Exp Med 183: 1797-1806, 1996.

14. Haraguchi N, Utsunomiya T, Inoue H, Tanaka F, Mimori K, Barnard GF and Mori M: Characterization of a side population of cancer cells from human gastrointestinal system. Stem Cells 24: 506-513, 2006.

15. Hirschmann-Jax C, Foster AE, Wulf GG, Nuchtern JG, Jax TW Gobel U, Goodell MA and Brenner MK: A distinct 'side population' of cells with high drug efflux capacity in human tumor cells. Proc Natl Acad Sci USA 101: 14228-14233, 2004.

16. Wang J, Guo LP, Chen LZ, Zeng YX and Lu SH: Identification of cancer stem cell-like side population cells in human nasopharyngeal carcinoma cell line. Cancer Res 67: 3716-3724, 2007.

17. Huang D, Gao Q, Guo L, Zhang C, Jiang W, Li H, Wang J, Han X, Shi Y and Lu SH: Isolation and identification of cancer stem-like cells in esophageal carcinoma cell lines. Stem Cells Dev 18: 465-473, 2009.

18. Bleau AM, Hambardzumyan D, Ozawa T, Fomchenko EI, Huse JT, Brennan CW and Holland EC: PTEN/PI3K/Akt pathway regulates the side population phenotype and ABCG2 activity in glioma tumor stem-like cells. Cell Stem Cell 4: 226-235, 2009.

19. Li H, Gao Q, Guo L and Lu SH: The PTEN/PI3K/Akt pathway regulates stem-like cells in primary esophageal carcinoma cells. Cancer Biol Ther 11: 950-958, 2011.

20. Chang FW, Fan HC, Liu JM, Fan TP, Jing J, Yang CL and Hsu RJ: Estrogen enhances the expression of the multidrug transporter gene ABCG2-Increasing drug resistance of breast cancer cells through estrogen receptors. Int J Mol Sci 18: E163, 2017.

21. Stacy AE, Jansson PJ and Richardson DR: Molecular pharmacology of ABCG2 and its role in chemoresistance. Mol Pharmacol 84: 655-669, 2013.

22. Fischer B, Frei C, Moura U, Stahel R and Felley-Bosco E: Inhibition of phosphoinositide-3 kinase pathway down regulates ABCG2 function and sensitizes malignant pleural mesothelioma to chemotherapy. Lung Cancer 78: 23-29, 2012.

23. Gao T, Mei Y, Sun H, Nie Z, Liu X and Wang S: The association of phosphatase and tensin homolog (PTEN) deletion and prostate cancer risk: A meta-analysis. Biomed Pharmacother 83: 114-121, 2016.

24. Wu H, Dai X and Wang E: Plumbagin inhibits cell proliferation and promotes apoptosis in multiple myeloma cells through inhibition of the PI3K/Akt-mTOR pathway. Oncol Lett 12: 3614-3618, 2016.

25. Rajkumar SV: Updated diagnostic criteria and staging system for multiple myeloma. Am Soc Clin Oncol Educ Book 35: e418-e423, 2016.

26. Huang FF, Wu DS, Zhang L, Yu YH, Yuan XY, Li WJ, Chen XP, Zhao XL, Chen FP and Zeng H: Inactivation of PTEN increases $\mathrm{ABCG} 2$ expression and the side population through the PI3K/Akt pathway in adult acute leukemia. Cancer Lett 336: 96-105, 2013.

27. Borowicz S, Van Scoyk M, Avasarala S, Karuppusamy Rathinam MK, Tauler J, Bikkavilli RK and Winn RA: The soft agar colony formation assay. J Vis Exp e51998, 2014.

28. Livak KJ and Schmittgen TD: Analysis of relative gene expression data using real-time quantitative PCR and the $2^{-\Delta \Delta C \mathrm{~T}}$ method. Methods 25: 402-408, 2001.

29. Sajadian S, Vatankhah M, Majdzadeh M, Kouhsari SM, Ghahremani MH and Ostad SN: Cell cycle arrest and apoptogenic properties of opium alkaloids noscapine and papaverine on breast cancer stem cells. Toxicol Mech Methods 25: 388-395, 2015. 
30. Jakubikova J, Adamia S, Kost-Alimova M, Klippel S, Cervi D, Daley JF, Cholujova D, Kong SY, Leiba M, Blotta S, et al: Lenalidomide targets clonogenic side population in multiple myeloma: Pathophysiologic and clinical implications. Blood 117: 4409-4419, 2011.

31. Zhou S, Schuetz JD, Bunting KD, Colapietro AM, Sampath J, Morris JJ, Lagutina I, Grosveld GC, Osawa M, Nakauchi H, et al: The ABC transporter Bcrp1/ABCG2 is expressed in a wide variety of stem cells and is a molecular determinant of the side-population phenotype. Nat Med 7: 1028-1034, 2001.

32. Kellner J, Liu B, Kang Y and Li Z: Fact or fiction-Identifying the elusive multiple myeloma stem cell. J Hematol Oncol 6: 91, 2013.

33. Guzel E, Karatas OF, Duz MB, Solak M, Ittmann M and Ozen M Differential expression of stem cell markers and ABCG2 in recurrent prostate cancer. Prostate 74: 1498-1505, 2014.

34. Sabnis NG, Miller A, Titus MA and Huss WJ: The efflux transporter ABCG2 maintains prostate stem cells. Mol Cancer Res 15: 128-140, 2017.

35. Wang H, Luo F, Zhu Z, Xu Z, Huang X, Ma R, He H, Zhu Y, Shao $\mathrm{K}$ and Zhao J: ABCG2 is a potential prognostic marker of overall survival in patients with clear cell renal cell carcinoma. BMC Cancer 17: 222, 2017.

36. Singh S, Bora-Singhal N, Kroeger J, Laklai H and Chellappan SP: $\beta$ Arrestin-1 and Mcl-1 modulate self-renewal growth of cancer stem-like side-population cells in non-small cell lung cancer. PLoS One 8: e55982, 2013.
37. Zhao R, Liu X, Wang Y, Jie X, Qin R, Qin W, Zhang M, Tai H, Yang C, Li L, et al: Integrated glycomic analysis of ovarian cancer side population cells. Clin Proteomics 13: 32, 2016.

38. Murota Y, Tabu K and Taga T: Requirement of ABC transporter inhibition and Hoechst 33342 dye deprivation for the assessment of side population-defined C6 glioma stem cell metabolism using fluorescent probes. BMC Cancer 16: 847, 2016.

39. Yan W, Du J, Du Y, Pu H, Liu S, He J, Zhang J and Hou J: Fenretinide targets the side population in myeloma cell line NCI-H929 and potentiates the efficacy of antimyeloma with bortezomib and dexamethasone regimen. Leuk Res 51: 32-40, 2016.

40. Wang Y, Yin C, Feng L, Ma L, Wei Y and Sheng G: Sorting, identification and enrichment of side population cells in THP-1 acute monocytic leukemia cells. Oncol Rep 29: 1923-1931, 2013.

41. Loh YS, Mo S, Brown RD, Yamagishi T, Yang S, Joshua DE, Roufogalis BD and Sze DM: Presence of hoechst low side populations in multiple myeloma. Leuk Lymphoma 49: 1813-1816, 2008.

This work is licensed under a Creative Commons Attribution-NonCommercial-NoDerivatives 4.0 International (CC BY-NC-ND 4.0) License. 